\title{
Fuzzy Pareto-optimal Solution to Fully Fuzzy Multi objective Linear programming problem
}

\author{
S. Mohanaselvi \\ Assistant professor, \\ Department of Mathematics, \\ SRM University, Kattankulathur, \\ Chennai - 603203, INDIA
}

\author{
K. Ganesan \\ Professor \& Head \\ Department of Mathematics, \\ SRM University, Kattankulathur, \\ Chennai - 603203, INDIA
}

\begin{abstract}
This paper proposes a new algorithm for the solution of fully fuzzy Multi objective linear programming problems involving triangular fuzzy number without converting them to equivalent classical problems. Based on the fuzzy ideal and fuzzy negative ideal solution of each single fuzzy objective function we propose an algorithm which provides a fuzzy Pareto-optimal solution for the given fully fuzzy multi objective linear programming problem. By the proposed method, the Decision Maker will have the flexibility of choosing $r \in[0,1]$ depending upon the situation and can obtain an improved fuzzy Pareto optimal solution. A numerical example is provided to illustrate the theory developed in this paper.
\end{abstract}

\section{Keywords}

Triangular fuzzy number, Fuzzy ranking, Fuzzy arithmetic, Fuzzy Multi objective linear programming problem.

\section{INTRODUCTION}

The classical mathematical programming problem is used to find an optimal solution for single objective function whereas many problems in real world may involve multiple objectives with conflicting nature. These types of problems can be formulated as Multi objective linear programming problems (MOLPP) and there is no best solution exists in this case because we cannot improve all objective functions simultaneously. Improvement of one objective function may result in worsening of at least one of the other objective functions. Many researchers have developed various algorithms for solving MOLPP. If the coefficients involved in the objective and constraint functions are imprecise in nature which is interpreted as fuzzy numbers, then the resulting problem is referred to as a fully fuzzy Multi objective linear programming problem (FFMOLPP). Multi objective with imprecise parameters make the problem complicated to solve them using traditional approaches.

Decision making under fuzzy environment was first proposed by Bellman and Zadeh. Zimmermann [13] proposed an application of fuzzy optimization techniques to linear programming problem with single and multi-objective functions. Lai and Hwang [7] classified the solution approaches of fuzzy multi objective decision making. Feyzan Arikan [5] introduced a two-phase approach for solving multi-objective programming problems with fuzzy coefficients. Hiroaki Kuwano [6] proposed a goal programming approach for solving FFMOLPP with possiblistic variables. Buckley [3] applied fuzzy Monto carlo method to generate a approximate solution for FFMOLPP. The method of fuzzy ranking was introduced by Miao-Ling Wang [8] to find the non dominated solution set to FFMOLPP and developed a technique of intra-parametric programming to solve the given problem. Xue-quan Li [12] proposed a two phase max-min fuzzy compromise approach to solve MOLPP. Chen and Chou [4] proposed a fuzzy approach to solve MOLPP. Omar Mohamed Saad [11] has suggested about the stability of the $\alpha$-pareto optimal solution in decision space for FFMOLPP. In this paper, we have proposed an algorithm to solve FFMOLPP without converting to crisp equivalent problem and obtained a fuzzy Pareto-optimal solution.

This paper is organized as follows: In section 2, we recall the basic concepts and the results of triangular fuzzy numbers and their arithmetic operations. In section 3, we introduce the Fuzzy Multi objective linear programming problem with triangular fuzzy number and related results. In section 4, we propose a new algorithm to find the fuzzy Pareto-optimal solution for the given FFMOLPP. In section 5, a numerical example is provided to illustrate the theory developed in this paper.

\section{PRELIMINARIES}

In this section we recall the basic concepts and the results of triangular fuzzy number and their arithmetic operations.

Definition 2.1 [10] A fuzzy set $\mathscr{C} c$ defined on the set of real numbers $\mathrm{R}$ is said to be a fuzzy number if its membership function $\mathbb{E} 6 \mathrm{R} \rightarrow[0,1]$ has the following characteristics:

(i) $\mathscr{Z}$ cis convex, that is

$$
\begin{aligned}
& \mathscr{Q}\left(\lambda \mathrm{x}_{1}+(1-\lambda) \mathrm{x}_{2}\right) \geq \min \left\{\mathscr{Q}\left(\left(\mathrm{x}_{1}\right), \mathscr{Q}\left(\mathrm{x}_{2}\right)\right\},\right. \\
& \text { for all } \mathrm{x}_{1}, \mathrm{x}_{2} \in R \text { and } \lambda \in[0,1] . \\
& \text { (ii) } \mathscr{Q} c \text { is normal i.e. there exists an } \mathrm{x} \in \mathrm{R} \text { such that }
\end{aligned}
$$

$$
\text { af } \mathrm{x})=1
$$

(iii) $\mathscr{R} c$ is Piecewise continuous.

Definition 2.2 [10] A fuzzy number $\mathscr{K}$ on $\mathrm{R}$ is said to be a triangular fuzzy number (TFN) or linear fuzzy number if its membership function $\mathscr{K} \% \mathrm{R} \rightarrow[0,1]$ has the following characteristics: 


$$
Q(x)=\left\{\begin{array}{cl}
\frac{x-a_{1}}{a_{2}-a_{1}}, & \text { for } a_{1} \leq x \leq a_{2} \\
\frac{a_{3}-x}{a_{3}-a_{2}}, & \text { for } a_{2} \leq x \leq a_{3} \\
0, & \text { elsewhere }
\end{array}\right.
$$

We denote this triangular fuzzy number by $\mathscr{Z}=\left(\mathrm{a}_{1}, \mathrm{a}_{2}, \mathrm{a}_{3}\right)$. We use $F(R)$ to denote the set of all triangular fuzzy numbers. Also if $\mathrm{m}=\mathrm{a}_{2}$ represents the modal value or midpoint, $\quad \alpha=\left(a_{2}-a_{1}\right)$ represents the left spread and $\beta=\left(a_{3}-a_{2}\right)$ represents the right spread of the triangular fuzzy number $\mathscr{C}=\left(\mathrm{a}_{1}, \mathrm{a}_{2}, \mathrm{a}_{3}\right)$, then the triangular fuzzy number $\mathscr{Q} c$ can be represented by the triplet $\mathscr{Q} \sigma=(\alpha, \mathrm{m}, \beta)$. i.e. $\mathscr{k}\left(\mathrm{a}_{1}, \mathrm{a}_{2}, \mathrm{a}_{3}\right)=(\alpha, \mathrm{m}, \beta)$.

Definition 2.3 [10] A triangular fuzzy number $\mathscr{Q} \in \mathrm{F}(\mathrm{R})$ can also be represented as a pair $\mathscr{Q} \in(\underline{\mathrm{a}}, \overline{\mathrm{a}})$ of functions a $(r)$ and $\bar{a}(r)$ for $0 \leq r \leq 1$ which satisfies the following requirements:

(i) $\underline{a}(r)$ is a bounded monotonic increasing left continuous function.

(ii) $\overline{\mathrm{a}}(\mathrm{r})$ is a bounded monotonic decreasing left continuous function.

(iii) $\underline{\mathrm{a}}(\mathrm{r}) \leq \overline{\mathrm{a}}(\mathrm{r}), 0 \leq \mathrm{r} \leq 1$

Definition 2.4 [10] For an arbitrary triangular fuzzy number $\mathscr{Q} \sigma=(\underline{\mathrm{a}}, \overline{\mathrm{a}})$, the number $\mathrm{a}_{0}=\left(\frac{\mathrm{a}(1)+\overline{\mathrm{a}}(1)}{2}\right)$ is said to be a location index number of $\&$. The two non-decreasing left continuous functions $\mathrm{a}_{*}=\left(\mathrm{a}_{0}-\underline{\mathrm{a}}\right), \quad \mathrm{a}^{*}=\tau_{\mathrm{a}_{0}}$; are called the left fuzziness index function and the right fuzziness index function respectively. Hence every triangular fuzzy number $\mathscr{Z} \sigma=\left(\mathrm{a}_{1}, \mathrm{a}_{2}, \mathrm{a}_{3}\right)$ can also be represented by $\mathscr{B}=\left(\mathrm{a}_{0}, \mathrm{a}_{*}, \mathrm{a}^{*}\right)$.

\subsection{Ranking of triangular Fuzzy Numbers}

Several approaches for the ranking of fuzzy numbers have been proposed in the literature. Abbasbandy and Hajjari [1] proposed a new ranking method based on the left and the right spreads at some $r$ - levels of fuzzy numbers by

$$
\operatorname{Mag}\left(\mathscr{a}=\frac{1}{2}\left(\int_{0}^{1}\left(\underline{\mathrm{a}}+\overline{\mathrm{a}}+\mathrm{a}_{0}\right) \mathrm{f}(\mathrm{r}) \mathrm{dr}\right)\right.
$$

Hence for any triangular fuzzy number $\mathscr{L}=\left(\mathrm{a}_{1}, \mathrm{a}_{2}, \mathrm{a}_{3}\right)=\left(\mathrm{a}_{0}, \mathrm{a}_{*}, \mathrm{a}^{*}\right)$ represented in terms of location index number, left fuzziness index function and the right fuzziness index function respectively, we define the magnitude of the triangular fuzzy number $\mathscr{Q}$ by

$$
\operatorname{Mag}(\&)=\frac{1}{2}\left(\int_{0}^{1}\left(\mathrm{a}^{*}+4 \mathrm{a}_{0}-\mathrm{a}_{*}\right) \mathrm{f}(\mathrm{r}) \mathrm{dr}\right)
$$

where the function $f(r)$ is a non-negative and increasing function on $[0,1]$ with $f(0)=0, f(1)=1$ and $\int_{0}^{1} f(r) d r=\frac{1}{2}$. The function $f(r)$ can be considered as a weighting function. In real life applications, $\mathrm{f}(\mathrm{r})$ can be chosen by the decision maker according to the situation. In this paper, for convenience we use $f(r)=r$.

For any two triangular fuzzy numbers $\mathscr{Q} b=\left(\mathrm{a}_{0}, \mathrm{a}_{*}, \mathrm{a}^{*}\right)$ and $\mathrm{b}=\left(\mathrm{b}_{0}, \mathrm{~b}_{*}, \mathrm{~b}^{*}\right)$ in $\mathrm{F}(\mathrm{R})$, we define the ranking of $\mathscr{C} c$ and $b^{C}$ by comparing the $\operatorname{Mag}(\mathscr{Q} C)$ and $\operatorname{Mag}\left(b^{C}\right)$ on $\mathrm{R}$ as follows:

(i) $\mathscr{d} \underline{f} b^{c}$ if and only if $\operatorname{Mag}(\mathscr{a}) \geq \operatorname{Mag}(b)$

(ii) $\mathscr{a} q \underline{p} b^{c}$ if and only if $\operatorname{Mag}(\mathscr{d}) \leq \operatorname{Mag}\left(b^{b}\right)$

(iii). $\mathscr{L} \approx \approx b^{c}$ if and only if $\operatorname{Mag}(\mathscr{M})=\operatorname{Mag}\left(b^{\circ}\right)$

\subsection{Arithmetic operation on triangular Fuzzy Numbers}

Ming Ma et al. [9] have proposed a new fuzzy arithmetic based upon both location index and fuzziness index functions. The location index number is taken in the ordinary arithmetic, whereas the fuzziness index functions are considered to follow the lattice rule which is least upper bound in the lattice L. That is for $a, b \in L$ we define $a \vee b=\max \{a, b\}$ and $\mathrm{a} \wedge \mathrm{b}=\min \{\mathrm{a}, \mathrm{b}\}$.

For arbitrary triangular fuzzy numbers $\mathscr{Q} \theta=\left(\mathrm{a}_{0}, \mathrm{a}_{*}, \mathrm{a}^{*}\right)$ and $\mathrm{b}^{\circ}=\left(\mathrm{b}_{0}, \mathrm{~b}_{*}, \mathrm{~b}^{*}\right) \quad$ and $*=\{+,-, \times, \div\}$, the arithmetic operations on the triangular fuzzy numbers are defined by

$$
\mathscr{G} * \mathrm{~b}^{\circ}=\left(\mathrm{a}_{0} * \mathrm{~b}_{0}, \mathrm{a}_{*} \vee \mathrm{b}_{*}, \mathrm{a}^{*} \vee \mathrm{b}^{*}\right)
$$

In particular for any two triangular fuzzy numbers $\mathscr{G}=\left(\mathrm{a}_{0}, \mathrm{a}_{*}, \mathrm{a}^{*}\right)$ and $\mathrm{b}^{\circ}=\left(\mathrm{b}_{0}, \mathrm{~b}_{*}, \mathrm{~b}^{*}\right)$, we define:

(i) Addition: $\quad \mathscr{a}+\mathrm{b}^{\circ}=\left(\mathrm{a}_{0}, \mathrm{a}_{*}, \mathrm{a}^{*}\right)+\left(\mathrm{b}_{0}, \mathrm{~b}_{*}, \mathrm{~b}^{*}\right)$

$$
=\left(a_{0}+b_{0}, \max \left\{a_{*}, b_{*}\right\}, \max \left\{a^{*}, b^{*}\right\}\right)
$$

(ii) Subtraction: $\mathfrak{a}^{\circ}-\mathrm{b}^{\circ}=\left(\mathrm{a}_{0}, \mathrm{a}_{*}, \mathrm{a}^{*}\right)-\left(\mathrm{b}_{0}, \mathrm{~b}_{*}, \mathrm{~b}^{*}\right)$

$$
=\left(a_{0}-b_{0}, \max \left\{a_{*}, b_{*}\right\}, \max \left\{a^{*}, b^{*}\right\}\right)
$$

(iii).Multiplication: $\mathbb{d} \propto \mathrm{b}^{\mathrm{C}}=\left(\mathrm{a}_{0}, \mathrm{a}_{*}, \mathrm{a}^{*}\right) \times\left(\mathrm{b}_{0}, \mathrm{~b}_{*}, \mathrm{~b}^{*}\right)$ 


$$
=\left(a_{0} \times b_{0}, \max \left\{a_{*}, b_{*}\right\}, \max \left\{a^{*}, b^{*}\right\}\right)
$$

(iv).Division $\mathscr{d} \bullet: \mathrm{b}^{\mathfrak{c}}=\left(\mathrm{a}_{0}, \mathrm{a}_{*}, \mathrm{a}^{*}\right) \div\left(\mathrm{b}_{0}, \mathrm{~b}_{*}, \mathrm{~b}^{*}\right)$

$$
=\left(a_{0} \div b_{0}, \max \left\{a_{*}, b_{*}\right\}, \max \left\{a^{*}, b^{*}\right\}\right)
$$

\section{FUZZY MULTI OBJECTIVE LINEAR PROGRAMMING PROBLEM WITH TRIANGULAR FUZZY NUMBER}

Let $F(R)$ be set of all triangular fuzzy numbers. A fuzzy multi objective linear programming problem with triangular fuzzy numbers is defined as follows:

$\max q_{\approx} \approx\left(Z_{1}^{o}, q_{2}^{o}, \ldots ., Z_{N}^{o}\right)^{\mathrm{T}}$

where $\mathscr{Z}_{1}=\sum_{\mathrm{j}=1}^{\mathrm{n}} \varepsilon_{\mathrm{j}} \ell_{\mathrm{j}}, Z_{2}=\sum_{\mathrm{j}=1}^{\mathrm{n}} \varepsilon_{\mathrm{j}} \ell_{\mathrm{j}}, \ldots \ldots . ., \mathscr{Z}_{\mathrm{k}}=\sum_{\mathrm{j}=1}^{\mathrm{n}} \varepsilon_{\mathrm{j}} \ell_{\mathrm{j}}$

subject to $\sum_{\mathrm{j}=1}^{\mathrm{n}} \mathscr{q _ { \mathrm { i } } \mathbb { X } _ { \mathrm { j } } \mathrm { p }} \quad \mathrm{b}_{\mathrm{i}}^{\circ} \quad$ for all $\mathrm{i}=1,2, \ldots ., \mathrm{m}_{0}$

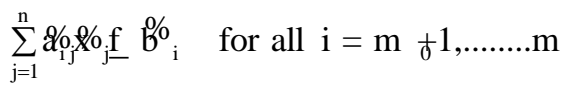

and $\otimes_{\mathrm{j}} \mathrm{f} \mathrm{B}^{\circ}$ for all $\mathrm{j}=1,2, \ldots ., \mathrm{n}$

Where $\alpha_{1 j}^{\circ}, \& \&_{j}, b_{i}^{o} \in F(R), i=1,2,3, \ldots \ldots m$ and

$\mathrm{j}=1,2,3, \ldots \ldots, \mathrm{n}$.

If $\&_{i 1}, \&_{\mathrm{j}}, \&_{\mathrm{j}}$ and $\mathrm{b}_{\mathrm{i}}^{\circ}$ are represented by location index number, left fuzziness index function and right fuzziness index function respectively, then the above problem can be rewritten as follows:

$\max \mathscr{Z} \approx\left(Z_{1}^{o}, Z_{2}^{o}, \ldots ., \mathscr{Z}_{\mathrm{N}}^{o}\right)$

where $Z_{1}^{o}=\sum_{\mathrm{j}=1}^{\mathrm{n}}\left\langle\left(\mathrm{c}_{1 \mathrm{j}}\right)_{0},\left(\mathrm{c}_{1 \mathrm{j}}\right)_{*},\left(\mathrm{c}_{1 \mathrm{j}}\right)^{*}\right\rangle \times\left\langle\left(\mathrm{x}_{\mathrm{j}}\right)_{0},\left(\mathrm{x}_{\mathrm{j}}\right)_{*},\left(\mathrm{x}_{\mathrm{j}}\right)^{*}\right\rangle$;

$$
\begin{aligned}
& \mathbb{Z}_{2}=\sum_{\mathrm{j}=1}^{\mathrm{n}}\left\langle\left(\mathrm{c}_{2 \mathrm{j}}\right)_{0},\left(\mathrm{c}_{2 \mathrm{j}}\right)_{*},\left(\mathrm{c}_{2 \mathrm{j}}\right)^{*}\right\rangle \times\left\langle\left(\mathrm{x}_{\mathrm{j}}\right)_{0},\left(\mathrm{x}_{\mathrm{j}}\right)_{*},\left(\mathrm{x}_{\mathrm{j}}\right)^{*}\right\rangle ; \\
& \mathcal{Z}_{\mathrm{k}}=\sum_{\mathrm{j}=1}^{\mathrm{n}}\left\langle\left(\mathrm{c}_{\mathrm{kj}}\right)_{0},\left(\mathrm{c}_{\mathrm{kj}}\right)_{*},\left(\mathrm{c}_{\mathrm{kj}}\right)^{*}\right\rangle \times\left\langle\left(\mathrm{x}_{\mathrm{j}}\right)_{0},\left(\mathrm{x}_{\mathrm{j}}\right)_{*},\left(\mathrm{x}_{\mathrm{j}}\right)^{*}\right\rangle
\end{aligned}
$$

Subject to the constraints

$$
\begin{array}{r}
\sum_{\mathrm{j}=1}^{\mathrm{n}}\left\langle\left(\mathrm{a}_{\mathrm{ij}}\right)_{0},\left(\mathrm{a}_{\mathrm{ij}}\right)_{*},\left(\mathrm{a}_{\mathrm{ij}}\right)^{*}\right\rangle \times\left\langle\left(\mathrm{x}_{\mathrm{j}}\right)_{0},\left(\mathrm{x}_{\mathrm{j}}\right)_{*},\left(\mathrm{x}_{\mathrm{j}}\right)^{*}\right\rangle \\
\mathrm{p}\left\langle\left(\mathrm{b}_{\mathrm{j}}\right)_{0},\left(\mathrm{~b}_{\mathrm{j}}\right)_{*},\left(\mathrm{~b}_{\mathrm{j}}\right)^{*}\right\rangle,
\end{array}
$$

for all $\mathrm{i}=1,2, \ldots . ., \mathrm{m}_{0}$

$$
\begin{aligned}
& \sum_{\mathrm{j}=1}^{\mathrm{n}}\left\langle\left(\mathrm{a}_{\mathrm{ij}}\right)_{0},\left(\mathrm{a}_{\mathrm{ij}}\right)_{*},\left(\mathrm{a}_{\mathrm{ij}}\right)^{*}\right\rangle \times\left\langle\left(\mathrm{x}_{\mathrm{j}}\right)_{0},\left(\mathrm{x}_{\mathrm{j}}\right)_{*},\left(\mathrm{x}_{\mathrm{j}}\right)^{*}\right\rangle \\
& \underline{\mathrm{f}}\left\langle\left(\mathrm{b}_{\mathrm{j}}\right)_{0},\left(\mathrm{~b}_{\mathrm{j}}\right)_{*},\left(\mathrm{~b}_{\mathrm{j}}\right)^{*}\right\rangle, \\
& \text { for all } \mathrm{i}=\mathrm{m}_{0}+1, \ldots \ldots . . \mathrm{m} \\
& \text { and }\left\langle\left(x_{j}\right)_{0},\left(x_{j}\right)_{*},\left(x_{j}\right)^{*}\right\rangle \underline{f} \oiint^{\circ} \text { for all } j=1,2, \ldots \ldots \ldots . . . n \text {. }
\end{aligned}
$$

Practically, it is difficult to reach fuzzy optimal for all objective functions subject to the given constraints in problem (1) and (2).

Definition 3.1 A fuzzy vector $\not \subset \in \mathbb{X}$ is said to be a fuzzy feasible solution if it satisfy the given constraints of the problem (2).

Definition 3.2 A fuzzy feasible solution $\mathbb{X} b$ is said to be a complete fuzzy optimal solution for (2) if there exists $\mathbb{X} \in \in \mathbb{X}$

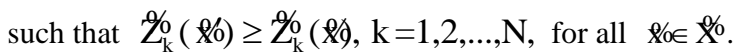

Since the objective functions conflict with each other, a complete fuzzy optimal solution that simultaneously maximize all the multiple fuzzy objective functions doesn't exist always. Thus instead of complete fuzzy optimal solution, a new solution concept called fuzzy Pareto-optimality is introduced for FFMOLPP.

Definition 3.3 A fuzzy feasible solution is said to be a fuzzy Pareto-optimal solution for (1) if there doesn't exist $\quad \mathbb{Q} b \in \mathbb{X}^{0}$

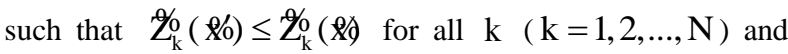
$\mathscr{Z}_{\mathrm{s}}(\& 0)<Z_{\mathrm{s}}(X)$ for at least one $\mathrm{s}$.

Definition 3.4 A fuzzy ideal solution of (1) is defined as a vector, whose components are composed by maximum value of each fuzzy objective function under the given constraints $Z^{*}=\left[Z_{1}^{*}, Z_{2}^{*}, \ldots ., Z_{k}^{o}\right]=\left[\max Z_{1}^{o}, \max Z_{2}^{o}, \ldots \ldots, \max Z_{N}^{o}\right]$.

Definition 3.5 A fuzzy negative ideal solution of (1) is defined as a vector, whose components are composed by minimum value of each fuzzy objective function under the given constraints,

$$
Z^{*}=\left[Z_{1}^{o}, Z_{2}^{o}, \ldots ., \mathscr{Z}_{\mathrm{k}}^{*}\right]=\left[\min Z_{1}^{o}, \min Z_{2}^{o}, \ldots \ldots, \min Z_{\mathrm{N}}^{o}\right]
$$

Definition 3.6 From fuzzy ideal and negative fuzzy ideal solution we can find the possible range $\left[\mathrm{Z}_{\mathrm{k}}^{-}, \mathrm{Z}_{\mathrm{k}}^{+}\right]$for the $\mathrm{k}^{\text {th }}$ fuzzy objective function. With $\mathrm{Z}_{\mathrm{k}}^{-}$and $\mathrm{Z}_{\mathrm{k}}^{+}$, define a nondecreasing linear membership function for the $\mathrm{k}^{\text {th }}$ fuzzy objective function as follows:

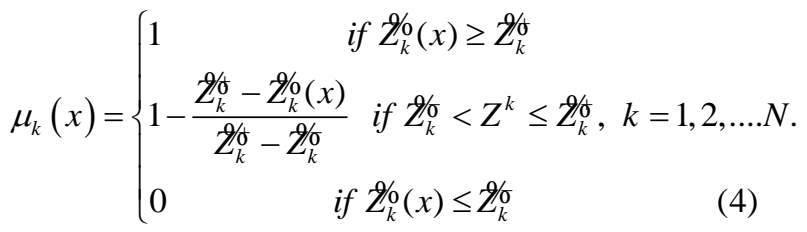




\section{A NEW ALGORITHM TO SOLVE FUZZY MULTI OBJECTIVE LINEAR PROGRAMMING PROBLEM}

An algorithm to find the fuzzy Pareto optimal solution to a fully fuzzy multi objective linear programming problem is presented as follows:

Step 1: Represent each fuzzy data $Q \mathscr{C}=\left(\mathrm{a}_{1}, \mathrm{a}_{2}, \mathrm{a}_{3}\right)$ in terms of $\mathscr{Q} G=\left(\mathrm{a}_{0}, \mathrm{a}_{*}, \mathrm{a}^{*}\right)$.

Step 2: Find the fuzzy ideal solution $\mathrm{Z}_{\mathrm{k}}^{+}$and fuzzy negative ideal solution $\mathrm{Z}_{\mathrm{k}}^{-}$of each single fuzzy objective function subject to the given constraints using fuzzy version of simplex algorithm proposed by Mohanaselvi and Ganesan [10].

Step 3: Define the membership of each fuzzy objective function's satisfaction degree using equation (4).

Step 4: Formulate a new problem for maximizing the satisfaction degree $\lambda$ of the final decision maker subject to the original constraints along with the additional constraint $\lambda \leq \mu_{k}(x), k=1,2, \ldots . N$. Solve this single objective model for obtaining the fuzzy Pareto-optimal solution of FFMOLPP. That is by the well known max-min operator, problem (1) can be reformulated as

$\max _{x \geq 0}\left\{\lambda=\min \left[\mu_{1}(x), \mu_{2}(x), \ldots \ldots, \mu_{N}(x)\right]\right\}$.

i.e. $\max \lambda$

such that $\lambda \leq \mu_{k}(x), k=1,2, \ldots . N$.

$$
\begin{aligned}
& \sum_{j=1}^{n} Q_{1 j} \ell_{j} \mathrm{p} \quad b_{i}^{\circ} \quad \text { for all } \mathrm{i}=1,2, \ldots \ldots, \mathrm{m}_{0} \\
& \sum_{j=1}^{n} Q_{1 \mathrm{j}} \ell_{j} \mathrm{f}-b_{i} \quad \text { for all } \mathrm{i}=\mathrm{m}_{0}+1, \ldots \ldots \ldots \mathrm{m} \\
& \lambda \in[0,1] \text { and } \ell_{j} \text { f } B \circ \text { for all } j=1,2, \ldots \ldots \ldots \ldots . . .
\end{aligned}
$$

\section{Theorem: 4.1}

A solution to the FFMOLPP (5) exists and is a fuzzy Paretooptimal solution to (1).

\section{Proof:}

Suppose $\mathbb{Q} b$ is not a fuzzy Pareto-optimal solution for problem (1), then there exists a fuzzy Pareto-optimal solution $\mathbb{8}^{\prime \prime}$.

Then, for every $k$, we have $\mathscr{Z}_{\mathrm{k}}\left(\mathbb{Q}^{\prime \prime}\right) \geq \mathcal{Z}_{\mathrm{k}}(\notin 0)$ and $q_{\mathrm{i}}^{o}\left(Q^{\prime \prime}\right) \geq \mathcal{Z}_{\mathrm{i}}^{\circ}(\mathrm{Q} 0), \mathrm{i}=1,2, \ldots, \mathrm{N}$.

That is for every $k$, we have $\mu_{k}\left(x^{\prime \prime}\right) \geq \mu_{k}\left(x^{\prime}\right)$ and $\exists i \in[1, N], \mu_{i}\left(x^{\prime \prime}\right)>\mu_{i}\left(x^{\prime}\right)$,

$$
\begin{aligned}
& \text { So } \lambda^{\prime}=\lambda\left(\mathrm{x}^{\prime}\right)=\min \left\{\mu_{1}\left(\mathrm{x}^{\prime}\right), \mu_{2}\left(\mathrm{x}^{\prime}\right), \ldots \ldots, \mu_{\mathrm{N}}\left(\mathrm{x}^{\prime}\right)\right\} \\
& \leq \min \left\{\mu_{1}\left(x^{\prime \prime}\right), \mu_{2}\left(x^{\prime \prime}\right), \ldots \ldots, \mu_{N}\left(x^{\prime \prime}\right)\right\}=\lambda\left(x^{\prime \prime}\right) \\
& \Rightarrow \lambda^{\prime} \leq \lambda^{\prime \prime}
\end{aligned}
$$

This shows that $\mathbb{R}$ is not the only optimal solution of (5), which is a contradiction. This contradiction proves that $\mathbb{Q b}$ is a fuzzy Pareto-optimal solution to (1).

\section{NUMERICAL EXAMPLE}

Consider an example discussed in Buckley.J.J et al [3]

$$
\begin{aligned}
& \max Z_{1}=(4,5,6) \ell_{p}+(2,3,4) \ell_{Q} \\
& \max Z_{2}=(1,2,3) \ell_{p}+(6,8,10) x_{2} \\
& \text { subject to }(0,1,2) \otimes_{\varphi}+(3,4,5) \ell_{Q} \leq(95,100,105) \\
& (2,3,4) \otimes_{p}+(1,2,3) \otimes_{Q} \leq(140,150,160) \\
& (3,5,7) \ell_{p}+(2,3,4) \ell_{q} \geq(180,200,220) \\
& (1,2,3) \otimes_{p}+(6,8,10) \otimes_{q} \geq(70,75,80)
\end{aligned}
$$$$
\text { and } \otimes_{\rho}, \otimes_{2} \geq 8 \text { ? }
$$

\section{Solution:}

Step 1: Representing the triangular fuzzy numbers in terms of left and right index function, we have

$$
\begin{aligned}
& \max Z_{1}=(5,1-r, 1-r) \ell_{\rho}+(3,1-r, 1-r) \ell_{Q} \\
& \max Z_{2}=(2,1-r, 1-r) \otimes_{\rho}+(8,2-2 r, 2-2 r) \otimes_{Q}
\end{aligned}
$$

subject to

$$
\begin{aligned}
& (1,1-r, 1-r) \ell_{p}+(4,1-r, 1-r) \ell_{2} \leq(100,5-5 r, 5-5 r) \\
& (3,1-\mathrm{r}, 1-\mathrm{r}) \mathrm{X}_{\mathrm{\rho}}+(2,1-\mathrm{r}, 1-\mathrm{r}) \mathbb{Q}_{Q} \leq(150,10-10 \mathrm{r}, 10-10 \mathrm{r}) \\
& (5,1-r, 1-r) \otimes_{\rho}+(4,1-r, 1-r) \otimes_{Q} \geq(200,20-20 r, 20-20 r) \\
& (2,1-r, 1-r) \otimes_{\rho}+(8,1-r, 1-r) \otimes_{Q} \geq(75,5-5 r, 5-5 r) \\
& \text { and } \mathrm{X}_{\rho}, \mathrm{X}_{Q} \geq \mathrm{B}^{\circ}, \quad \mathrm{r} \in[0,1]
\end{aligned}
$$

Step 2: Using fuzzy version of simplex algorithm proposed by Mohanaselvi and Ganesan [10], the fuzzy ideal and fuzzy negative ideal solution of each single fuzzy objective function subject to the given constraints is given by:

Table 5. 1. Fuzzy Ideal and Fuzzy Negative ideal solutions

\begin{tabular}{|c|l|l|}
\hline & $\max$ & $\min$ \\
\hline$Z_{1}$ & $(250,20-20 r, 20-20 r)$ & $(200,20-20 r, 20-20 r)$ \\
\hline$Z_{2}$ & $(200,20-20 r, 20-20 r)$ & $(80,20-20 r, 20-20 r)$ \\
\hline
\end{tabular}

Since the objective functions conflict with each other, a complete fuzzy optimal solution that simultaneously maximize all the multiple fuzzy objective functions doesn't exist always. Thus instead of complete fuzzy optimal solution, a new solution concept called fuzzy Pareto-optimality is introduced for FFMOLPP.

Step 3: Define the membership of each fuzzy objective function's $Z_{1}$ and $Z_{2}$ satisfaction degree.

Step 4: Now, solve the following problem for obtaining the fuzzy Pareto optimal solution of the given fully fuzzy multi objective linear programming problem. 
Solving the above problem we get the Solution as:

$$
\begin{aligned}
& \lambda=0.9107, \ell_{1}=(41.07,20-20 r, 20-20 r) \text { and } \\
& \ell_{2}=(13.39,20-20 r, 20-20 r) .
\end{aligned}
$$

Table 5. 2. Comparison study of the proposed method

\begin{tabular}{|c|c|c|c|}
\hline & $\lambda$ & $\max Z_{1}$ & $\max Z_{2}$ \\
\hline $\begin{array}{l}\text { Proposed } \\
\text { method }\end{array}$ & 0.9107 & $\begin{array}{l}Z_{1}= \\
\left(\begin{array}{r}245.5,20-20 r, \\
20-20 r\end{array}\right)\end{array}$ & $\left.\begin{array}{r}Z_{2}= \\
189.29,20-20 r, \\
20-20 r\end{array}\right)$ \\
$=\left(\begin{array}{r}225.5,245.5, \\
265.5\end{array}\right)$ & $=\left(\begin{array}{r}169.29,189.29, \\
209.29\end{array}\right)$ \\
\hline $\begin{array}{c}\text { Buckley's } \\
\text { Method }\end{array}$ & 0.5 & $\left.\begin{array}{c}Z_{1}= \\
183.43,254.67, \\
319.08\end{array}\right)$ & $\left.\begin{array}{l}Z_{2}= \\
197.73,225.28, \\
305.27\end{array}\right)$ \\
\hline
\end{tabular}

We see that the largest possible range of objective functions $Z_{1}$ and $Z_{2}$ are $[200,250]$ and $[80,200]$ respectively by the proposed method. When $r=1$, the solution becomes $Z_{1}=245.5$ and $Z_{2}=189.29$ which lies inside the possible range where as it is not so in the case of Buckley [3].

\section{CONCLUSION}

In this study we have introduced a new algorithm for solving fully fuzzy Multi objective linear programming problem with triangular fuzzy number without converting to equivalent classical problem. The triangular fuzzy numbers are represented in terms of location index number, left fuzziness index function and right fuzziness index function respectively. Multi objective linear programming with imprecise parameters makes the problem complicated and hence the traditional approaches fails to give a solution to those problems. Based on the fuzzy ideal and fuzzy negative ideal solution of each single fuzzy objective function of the given fuzzy MOLP, the proposed algorithm provides a fuzzy Paretooptimal solution for the given fully fuzzy multi objective linear programming problem in an improved way. This idea can be extended for solving multi-level multi objective linear programming problem with fuzzy coefficients. A numerical example discussed by Buckley [3] is solved using the proposed method without converting the given problem to crisp equivalent problem. It is to be noted that by applying the proposed method, the Decision Maker have the flexibility of choosing $r \in[0,1]$ depending upon the situation and he can obtain the fuzzy Pareto optimal solution for the given problem.

\section{ACKNOWLEGEMENT}

The authors are grateful to the anonymous referees and the editors for their constructive comments and valuable suggestions.

\section{REFERENCES}

[1] Abbasbandy.S and Hajjari. T, A new approach for ranking of trapezoidal fuzzy numbers, Computers and Mathematics with Applications, 57, 413-419, (2009).

[2] Bellman, R.E and Zadeh, L.A., Decision-making in fuzzy environment, Management sciences, 17(4) (1970), 141164.

[3] Buckley.J.J et al Monto carlo Method in Fuzzy Optimization, Springer-verlang Berline Heidelberg ,STUDFUZZ 22, 81-88, 2008

[4] H.K.Chen, H.W.Chou, Solving multiobjective linear programming problem - a generic approach, Fuzzy sets and systems, 82 (1996) 35-38.

[5] Feyzan Arikan, Zulal Gungor, A two phase approach for multi-objective programming problems with fuzzy coefficients, Information sciences, 177(2007), 51915202 .

[6] Hiroaki kuwano, On the fuzzy multi-objective linear programming problem: Goal programming approach, Fuzzy sets and systems, 82 (1996), 57-64.

[7] Y.J.Lai and C.L.Hwang, Fuzzy Multiple Objective Decision Making, Lecture Notes in Economics and Mathematical systems, Vol.404 (springer,Berlin, 1994).

[8] Miao-Ling Wang, Finding the nondominated solution set of a fuzzy multiobjective linear program by using fuzzy ranking method, Ming Hsin Journal,Volume 31,(2005),137-145.

[9] Ming Ma, Menahem Friedman, Abraham kandel, A new fuzzy arithmetic, Fuzzy sets and systems, 108,8390,(1999).

[10] S. Mohanaselvi and K. Ganesan, Fully Fuzzy linear programs with triangular fuzzy number, International journal of Mathematical Archieve, 3(5),(2012),18381845.

[11] Omar Mohamed saad, Stability on multi objective linear programming problem with fuzzy parameters, Fuzzy sets and systems, 74 (1995), 207-215.

[12] Xue-quan Li, Bo Zhang, Hui Li, Computing efficient solutions to fuzzy multiple objective linear programming problems, Fuzzy sets and system,157(2006),1328-1332.

[13] Zimmermann H. J., Fuzzy programming and linear programming with several objective functions, Fuzzy sets and systems, 1(1978), 45-55. 